\title{
Mental health, stress and the contemporary metropolis
}

\author{
Nikolas Rose
}

Can contemporary developments in the life sciences help us understand the ways in which 'adversity' shapes mental health conditions in the heterogeneous conglomerations we call cities? Many have pointed to the evidence that those living in cities are more likely to be diagnosed with mild, moderate and severe mental disorders than those living in rural settings. But it has proved difficult to identify precisely what it is in the urban experience that leads to these elevated rates. The same is true of research that has addressed urban mental health in migrant and refugee populations, in the global north and in megacities such as Mumbai, Shanghai and São Paulo in the global south. Some rates are elevated in some migrants, sometimes only in the second generation, but the findings are equivocal, and migration itself does not seem to be a consistent causal factor for mental ill health - indeed sometimes quite the reverse.

Can we link biomedical explanations with sociological and anthropological research to understand the ways in which the experiences of poverty, inequality, precarity, gender discrimination, racism, stigma, social exclusion, isolation, threat and violence lead many to mental distress? Can we extend such an analysis beyond these traditional 'social factors' to encompass such issues as the built environment, the capacities and limits to individual and collective life engendered by the urban infrastructure, and the urban 'sensorium' of noise, smell, touch and microbes? If we understood these mechanisms better would we be better able to advise on policies to mitigate mental distress in urban environments and on practices likely to promote recovery? Could such an approach inform strategies to create 'healthy, safe and sustainable cities' ${ }^{\text {'1 }}$ through 
measures ranging from architecture and urban design, through housing, transport and mobilities, to the management of biophysical environments from microbes to air quality? Could we 'translate' such biosocial and biocultural research to policies and practices, and if so, how would questions such as urban justice or the 'right to the city' be transformed? Could we draw upon our genealogical grasp of urban biopolitics to shape another biopolitics of the urban? To paraphrase Didier Fassin (Fassin, 2009), is another politics of life possible?

These are the questions that my research group is addressing in our programme of research on 'The Urban Brain'. ${ }^{2}$ This research programme was initiated in 2013 with a grant from the Transformative Research Scheme of the Economic and Social Research Council (ESRC), which enabled us to hold four international workshops and develop the framework for international collaborations around the theme of mental health, migration and the megacity. The first substantive research project focuses on rural-to-urban migration in Shanghai, where we are working with partners from the Department of Public Health at Fudan University on a three-year study funded from the ESRC's Newton Fund. We are using the case of São Paulo, which has a very different pattern and temporality of migration, as a comparator, working with colleagues from the Department of Psychiatry at University of São Paulo Medical School, and are working with colleagues at the Wellesley Institute in Toronto to explore the implications of the very different patterns of migration in Toronto. We are fortunate that, at King's College London, we are also able to make comparisons with the results from the South East London Community Health (SELCoH) study, carried out in the south London boroughs of Southwark and Lambeth, both of which have very large populations of transnational migrants. ${ }^{3}$ These experimental empirical investigations explore the mental and cerebral consequences of two of the central transformations that characterise our present - urbanisation and migration.

\section{Reasons to be cheerful, one, two, three, four, five}

Our 'urban brain' experiments start from five 'reasons to be (cautiously) cheerful', as follows. ${ }^{4}$

First, there are developments in the life sciences and neuroscience that recognise the limits of the paradigm of social research that has dominated for the last fifty years (disussed in detail in Rose and Abi-Rached, 2013; 
Rose and Abi-Rached, 2014). This is leading to a gradual transformation of styles of thought, away from molecular reductionism, with its focus on experiments on animal models in laboratories or isolated individuals in brain scanners, towards approaches that try to relocate the human animal in its milieu, and to a recognition of the constitutive transformations between 'the biological' and 'the sociocultural' across the 'life course'. The words are becoming familiar. Epigenetics, the processes of gene activation and de-activation across an individual's life, in response to inputs from the milieu. Neuroplasticity, the fact that neural circuits are shaped and reconfigured across the life course, both in terms of structure and in terms of function in response to experiences. Neurogenesis, the production and integration of new nerve cells, to replace those that are dead or damaged, a process which can be stimulated or inhibited by factors from exercise to diet. The microbiome, the millions of bacteria which inhabit human and other animals and play an important part in maintaining both physical and mental health, and which are acutely sensitive to the environment and form of life of the human being that they live with. The exposome, the cumulative effect on the organism of environmental insults from pollution and radiation to diet and noise. We may already be bored with the cliché 'how adversity gets under the skin', but social scientists should embrace these developments, not least because the conceptions of the social, the cultural and indeed of 'adversity' in such emerging styles of thought are both etiolated and imprecise.

Second, some social scientists now recognise that not all references to the biological are reductionist, determinist, fatalist and so forth. Humans are indeed biosociocultural creatures, whose capacities, forms of life and life course are not merely discursively enabled and performed, but are shaped in fundamental ways by the fact that they are evolved living creatures, evolved for language, sociality, culture. Pioneers in this regard - Elizabeth Grosz, Elizabeth Wilson and Margaret Lock, and in another way, Ted Benton - are no longer isolated voices (Grosz, 1994; Wilson, 2015; Lock and Kaufert, 2001; Benton, 1993). We now have multiple manifestoes rediscovering the biological roots of the social sciences, seeking to reframe sociological theory to recognise the significance of the biological and challenging the illusory boundary between the organism and its milieu (e.g. Meloni, Williams and Martin, 2016). We should welcome this 'entente cordiale' between the two sciences of life. But we have few studies of specific problems that embody this ethos, and few attempts to link this recognition of the biosociocultural character of 
human societies with the central questions of the contemporary social sciences concerning power, inequality and injustice.

Third, when it comes to mental health, there is increasing recognition of the role of 'social determinants'. We can see this in the recent report written for the World Health Organization (WHO) by Michael Marmot and his group on 'the social determinants of mental health' (WHO, 2014), and, tentatively, in recent publications by psychologists and psychiatrists, such as the recent report of the Lancet Commission on 'The Future of Psychiatry' (Bhugra et al., 2017). The WHO report is clearest, pointing to systematic reviews that consistently show that common mental disorders such as depression and anxiety 'are distributed according to a gradient of economic disadvantage across society': the poor and disadvantaged suffer disproportionally from common mental disorders and their adverse consequences (Campion et al., 2013; Lund et al., 2010; WHO, 2014), both in low-resource settings (Patel et al., 2010; Patel and Kleinman, 2003; Fryers, Melzer and Jenkins, 2003) and in countries in the global north (Lund et al., 2010). The implication is that mental health workers, including some psychiatrists, should move outside the clinic to collaborate with others as workers in public health. But while studies certainly demonstrate social determinants, they are also inconclusive and contradictory about exactly which aspects of social disadvantage are important - bad experiences in childhood, financial stress, poor housing, bad education, insecure employment, social isolation, etc.; each is sometimes found to be significant, and sometimes not. They are also unclear about whether objective material conditions account for this gradient, or whether subjective responses to those material conditions are decisive a point to which I will return. The WHO report does rise to the challenge of mechanisms, however, suggesting that the mechanism that translates these diverse forms of disadvantage to mental distress is 'stress', especially prolonged and unrelieved, or 'toxic' stress, and that the malign effects of 'stress' can be 'buffered' by various forms of social support; again, I will return to this. ${ }^{5}$

Fourth, if we accept that there are social, cultural, environmental determinants of mental distress, we can now use novel research methodologies to grasp these in more detail. We have cohort studies that take epigenetic data alongside biographical, social and mental health measures across the life course, and help us understand the later life consequences of early adversities. ${ }^{6}$ We have geomapping, which can produce much more accurate spatialisations of the relations between 
mental ill health and a range of environmental exposures than were possible before. We have mental health apps, coupled with geomapping, which can trace an individual's experienced mental health state and link it to their precise location in a city, to whether their anxiety may be more intense in crowds and less so in spaces, to the mental health consequences of long commutes or hazardous workspaces and much more. ${ }^{7}$ And, perhaps less well known, we have a growing body of research methodologies enabling us to explore the experience of mental distress from the perspective of actual or potential psychiatric service users: the rise of new methods and concepts from the service user's perspective challenges the 'monologue of reason over madness' and the authority of 'expert' knowledge which it embodies (Campbell and Rose, 2010; Rose, 2017).

Fifth, we have seen the emergence - or I should say the re-emergence of 'mental ill health in the city' as a governmental domain: a range of arguments that point to the prevalence of mental distress in specific cities, draw attention to its personal, familial, social and economic consequences, and prioritise policy interventions to address it. There is a long history of urban biopolitics of mental disorder, from the eugenic policies in the United States (US), Canada and many other cities in the late nineteenth and early twentieth centuries, through the ecological biopolitics linked to the Chicago School, to the mental hygiene movements of the inter-war years. Today, high-profile urban mental health programmes such as ThriveNYC in New York, Thrive LDN in London, the 'Big Anxiety' in Sydney and many others also start from arguments that the rate of mental ill health in the city is a major challenge. But they believe that it is possible, indeed necessary, to use urban policy to make the city 'thrive' again. These programmes contain a recurrent mix of policies. Take the six principles of ThriveNYC:

- 'Change the culture' to enable New Yorkers to have an open conversation about mental health, training people in ways of responding to those in mental distress and shifting the focus of mental health towards public health.

- 'Act early', prioritising preventive intervention especially in families and schools, repeating the familiar argument that earlier is almost always better, and early intervention services are key.

- 'Close treatment gaps' by providing mental health care provisions locally in every community and thus improving access and impact, 
although a lot of the specific actions concern homelessness and opioid addiction.

- 'Partner with communities', embracing the wisdom and strength of local communities, to create effective and culturally competent solutions, which seems to amount to trying to create pathways to specialist care for those with mental health needs.

- 'Use better data', by collecting reliable city-wide data on the health and emotional wellness of children and the factors affecting it, and establishing a mental health innovation laboratory to analyse and interpret the data.

- 'Strengthen government's ability to lead' by creating a mental health council to engage the community and implement the plans. The New York City Mental Health Commissioner Gary Belkin is passionately committed to making New York City a place where citizens can 'thrive', and this urban biopolitics of mental health certainly departs from its many predecessors in many ways, and is being emulated in a number of other cities, notably London and Toronto. But it is not clear that it draws upon social science research, or any of the 'biosocial' developments I have discussed here.

Nonetheless, in the confluence of these five dimensions, it seems to me that we are at an important point at which 'research and its results, despite their often intangible means, [might] make urban life visible through a different lens, [and] create concrete new urban experiences' in which research has a capacity to change the experience of urban life and urban mental distress. ${ }^{8}$ Now as soon as one tries to incorporate social experiences and neurobiological mechanisms into a diagram to depict the relations between adversity and mental ill health, things get extremely complicated. ${ }^{9}$ Faced with such complexity, which is probably the reality, it is no wonder that some yearn for the radical simplification of the laboratory experiment, despite the repeated evidence of the impossibility of translating the results from the protected and artificial space of the laboratory to the wild world outside (Callon, Lascoumes and Barthe, 2009). It is also no wonder that some take a different route and say: 'who cares about the detailed "causal architecture": we know at a population level that poverty, disadvantage, bad housing, insecure employment and the like are highly correlated with mental ill health, so why sweat over the details? When those major determinants have been mitigated, we can worry about how to deal with 
the pockets of mental distress that remain.' This view is undoubtedly appealing, and appears, in a more sophisticated form, in the arguments by Bruce Link and Jo Phelan about what they term 'fundamental causes' (Phelan and Link, 2013): research that tries to tease out the details of mechanisms, they say, often ignores what puts individuals 'at risk of risk'. 'Social factors such as socioeconomic status and social support are likely "fundamental causes" of disease that, because they embody access to important resources, affect multiple disease outcomes through multiple mechanisms, and consequently maintain an association with disease even when intervening mechanisms change' (Link and Phelan, 1995: 80).

\section{But suppose we cared about mechanisms}

Are mechanisms irrelevant once one finds correlations? No: mechanisms remain crucial. First, in the absence of an understanding of mechanisms we may think we can do nothing prior to a major transformation of our societies, since small changes leave fundamental causes untouched. Second, we may actually misidentify the roots of the problem and hence misdirect our interventions: consider, for example, the difference between interventions that result from the belief that mental disorders arise from multiple inherited genetic variations affecting the activity of neurotransmitters such as serotonin and dopamine, and those that might result from the belief that the mechanism is a stress-related disruption of the microbiome and the immune system, leading to increased susceptibility to chronic inflammation of the brain, as in some current research on schizophrenia and other serious disorders (Müller et al., 2015; Alam, Abdolmaleky and Zhou, 2017). ${ }^{10}$

The WHO report (2014) regarded adverse social conditions as causal, but studies are ambiguous about which dimensions of social disadvantage are key: education, food insecurity, housing, socio-economic status and financial stress exhibit a relatively consistent and strong association, while other simpler variables such as income and employment were more equivocal (Lund, 2014; Burns, 2015). The same is true of studies that have focused on the specific question of mental ill health in the urban environment, whether in relation to severe disorders such as schizophrenia (Krabbendam and Van Os, 2005) or on 'common mental disorders' such as depression and anxiety (Paykel et al., 2000; Gong et al., 2016; Fone et al., 2014). 
Nonetheless the WHO report suggests a mechanism: 'stress'. Now the notion of stress has been used in everyday speech going back to the eighteenth century: stress as hardship, straits, adversity, affliction. In the nineteenth century many physical and emotional ills were blamed on the increasing stress of modern life (Jackson, 2013). By the end of the nineteenth century, the rapidly expanding cities were thought of as particularly stressful places. From the 1920s onwards, building on the work of Walter Cannon, researchers used animal models to understand the biology of stress, and Hans Selye announced his 'general adaptation syndrome': whatever the cause of stress in his rats - heat, cold, injections of noxious substances, etc. - the biological response was the same: stimulation of the adrenal glands to prepare the animal for 'fight or flight' (Selye, 1936). And when this stress response was prolonged in situations where the animal was unable to escape, this led to all manner of physical and behavioural pathologies.

This work was taken up in relation to overcrowding in the experiments of John Calhoun, examined by Ed Ramsden (Adams and Ramsden, 2011; Ramsden, 2011; Cantor and Ramsden, 2014; Ramsden, 2014). ${ }^{11}$ Behavioural pathologies in overcrowded rat colonies led to the development of 'behavioural sinks', to use Calhoun's term, where female rats 'fell short of their maternal functions', infant mortality increased, and, for the males, 'behavior disturbances ranged from sexual deviation to cannibalism and from frenetic overactivity to a pathological withdrawal from which individuals would emerge to eat, drink and move about only when other members of the community were asleep. The social organisation of the animals showed equal disruption.'

For those involved in city planning in the US in the 1960s and 1970s, the stress responses to overcrowding in rats had obvious lessons for humans, and this generated a fierce debate about the effects of urban density. These questions were taken up by a large interdisciplinary group in the US containing many leading social scientists and urbanists, the Committee on Physical and Social Environmental Variables as Determinants of Mental Health, which met biannually from 1956 to 1968 (Duhl, 1963). The language of stress became a potent and highly transferrable framework for coding the challenges to human health in multiple domains - in the military, the factory, in everyday life in the modern world - and in the city. International conferences were held in the US and the United Kingdom (UK), extensive volumes were published linking stress to all manner of diseases of the body and of the 
mind (Kirk, 2014), and it seemed that almost all key figures - biologists, psychiatrists, psychologists, physiologists, ethnologists, sociologists, architects and planners - sought to think through the ways to link the physical and social spaces of the city to the mental health of citizens via the intermediary of stress.

These endeavours in the 1950s, 1960s and 1970s by and large came to a pretty depressing end. This was for three reasons. The first was that although most of the participants used the term 'stress', they meant very different things by it. Interdisciplinary conversations were achieved at the price of recognising and coming to terms with these differences. Secondly there was no agreement as to whether stress was something objective in the physical or social environment, or a subjective perception and experience, such that what was stressful for one person or one social or cultural or ethnic group, or women rather than men, or the old rather than the young, was not stressful to others. There was much research on 'stress' in urban environments: the stress of commuting, noise, crowding and much more. Amos Rapoport was probably speaking for most researchers on urban stress in humans when he concluded, in 1978, that stress was not 'objective' but depended on a subjective perception of particular environments and hence was shaped by culture, biography, language, symbols and meaning (Rapoport, 1978). ${ }^{12}$ Thirdly, while most agreed that stress occurs when the organism's homeostatic mechanisms are unable to maintain a state of dynamic equilibrium, which impairs psychological functioning, it was by no means clear how such stress might lead to physical disease or mental disorder.

Many abandoned stress research for these reasons. But by the 1990s, stress came to the fore again, equipped with an updated neurobiological foundation. In their much cited paper of 1993, Bruce McEwen and Elliot Stellar argued that prolonged experience of stress in humans increased 'allostatic load' - the 'strain on the body produced by repeated ups and downs of physiologic response [to stress], as well as by the elevated activity of physiologic systems under challenge, and the changes in metabolism and the impact of wear and tear on a number of organs and tissues' and argued that prolonged increases in allostatic load led to 'specific changes in the immune and cardiovascular systems and neural and adipose tissues that produce specific disease outcomes' (McEwen and Stellar, 1993: 2094). Crucially, stress was now a mental and indeed cerebral phenomenon. As McEwen puts it in a paper entitled 'Brain on stress: How the social environment gets under the skin', the 
brain is 'the central organ of stress and adaptation': 'Stress is a state of the mind, involving both brain and body as well as their interactions' (McEwen, 2012: 17180).

The brain shapes what is perceived as stressful, and determines the consequences of that stress. The social and the physical environment gets 'under the skull' because of the way it is perceived and understood (Davidson and McEwen, 2012). In humans, McEwan argues, culturally shaped perceptions that one is in a stressful, pressured or threatening situation act on the structural plasticity of the hippocampus and other brain regions, notably the amygdala, the prefrontal cortex and the nucleus acumbens. A key mechanism for such changes is epigenetic that is to say, via the regulation of gene expression. Animal studies show that both acute and chronic stress produces neuronal changes, inhibiting neurogenesis and affecting synaptic turnover, spine density, branching and length of neuronal axons; many of these studies have been supported by neuroimaging studies in humans. Repeated stress 'causes functional changes in neural circuitry in the hypothalamus' (Senst and Bains, 2014: 102), which alters activation of the immune system: continued activation of the immune system produces cytokines that act on other cells, leading to behaviour changes and depression-like symptoms (Dantzer et al., 2008; Pariante and Lightman, 2008) - popularly known as the inflamed brain' or 'inflamed mind' thesis. ${ }^{13}$

Many focus on the long-term effects of 'toxic' stress in childhood, which, McEwen argues, has 'implications for understanding health disparities and the impact of early life adversity and for intervention and prevention strategies' (McEwen, 2013: 673). Writing with his brother Craig, a sociologist, he makes the dubious claim that toxic stress in childhood can help account for the reproduction of poverty in families across generations in the US - dubious when many factors such as poor schooling, financial hardship and racial discrimination seem more obvious and proximal causes.

As Manning has pointed out (2019), the evidence that allostatic load is consistently linked to broad indices of social deprivation such as socio-economic status is equivocal, at least in part because of the heterogeneity of measures used (Dowd, Simanek and Aiello, 2009; Johnson, Cavallaro and Leon, 2017). Nonetheless, such research seems to identify one pathway for the corporeal and cerebral consequences of adversity. In a paper entitled 'Six paths for the future of social epidemiology', Sandro Galea and Bruce Link argued that if social epidemiology was to 
distinguish itself from other branches of epidemiology it had to address causes and mechanism (Galea and Link, 2013). As already mentioned, Link, with Jo Phelan, has long argued that socio-economic status is a 'fundamental social cause' (Link and Phelan, 1995; Phelan and Link, 2010), but Galea focused on the role of epigenetic changes that modify gene expression and activated molecular pathways to mental disorder. His group found distinctive gene methylation profiles in residents of a Detroit neighbourhood who had been assaulted, and suggested that 'cumulative traumatic burden may leave a molecular footprint in those with [PTSD]' (Galea, Uddin and Koenen, 2011: 402) and more generally that 'different aspects of the urban environment are distinctly and variably linked to brain structure, function, and hence phenotype' (Galea, 2011: 859). But some individuals and groups in incredibly 'stressful' circumstances seem to survive and thrive: why?

\section{Buffering stress}

The WHO report suggests that the link between social status and mental disorder may be shaped by 'the level, frequency and duration of stressful experiences and the extent to which they are buffered by social supports in the community' and that those 'lower on the social hierarchy' are more likely to be subject to such experiences, and have access to fewer buffers and supports (WHO, 2014: 16-18). This idea of 'buffering' by social supports draws upon the one seemingly sociological concept that regularly figures in neuropsychiatric research: 'social capital'. Many researchers argue that high 'social capital' is conducive to mental health because it is protective (Muntaner, 2004; Kelleher, 2003; Sartorius, 2003; Dannenberg et al., 2003; Saegert and Evans, 2003; McKenzie, Whitley and Weich, 2002; Henderson and Whiteford, 2003). This is not the place to trace the complex roots of this idea; in this literature on mental health it is a fuzzy concept, oscillating between attention to the material conditions of life - stable families, established communities, social integration, access to mental care and so forth - and a focus on what is termed 'cognitive social capital', that is to say an individual's feelings of trust and beliefs that he or she exists in a web of mutual obligations and reciprocality. Sadly, while it is initially appealing - for who would not believe that such social bonds were conductive to mental health and protective in times of adversity? - the evidence is inconclusive. But the results of empirical investigations are confused, not only because of the variety of ways in 
which this notion has been conceptualised, but by the diversity of ways it has been operationalised in attempts to measure it, and because of the naivety in thinking of social capital 'in isolation from the political and historical context of any given society' (Almedom, 2005: 946).

We can see the ambiguous consequences of such a focus on 'buffers' in the WHO report on social determinants. The report suggests that 'toxic stress' in childhood - strong and frequent or prolonged adversity such as abuse, neglect, violence and economic hardship, over a long period without adequate support - is 'buffered by social support provided by loving, responsive and stable relationships with a caring adult' (WHO, 2014: 18) which is less likely if mothers are young, socially or economically disadvantaged, experiencing a hostile or violent environment or themselves suffering from mental health problems. Schooling and home support throughout childhood, they suggest, can build 'emotional resilience', and this too is less likely for children in families living in poverty and stressful circumstances: hence they argue that efforts to support poorer families, especially those where adults themselves are suffering poor mental health will 'help disrupt the intergenerational transfer of inequities' (WHO, 2014: 27). Many would agree with their key message that 'Mental health and many common mental disorders are shaped to a great extent by the social, economic and physical environments in which people live.' But it is easy to interpret these arguments about the key role of mothers and families in childhood as a reprise of earlier views on 'the cycle of deprivation' (Joseph, 1972) rewritten in neural terms, views that led to policies directed at poor families themselves rather than at the social conditions that thrust them into poverty (Welshman, 2007).

\section{Another biopolitics}

Research on stress is of interest because it illustrates the long history of interactions between social scientists and life scientists. It is also interesting because it seems to have identified mechanisms by which a variety of subjective experiences, perceived as stressful as a result of individual biography, culturally shaped meanings and environmental insults, can be translated into neurobiological configurations with deleterious consequences for brain and body. But the research also raises conceptual questions of how we might develop a finer-grained, ethnographically informed analysis of the accumulation of urban situations that constitute stress and their spatial, temporal and sensorial characteristics. In 
psychiatric research, stress usually appears to be an individual phenomenon. But sociological and ethnographic investigations should map out the ways in which the experience of stress, and of poverty, exclusion, isolation, racism and violence, are shaped by cultural narratives and beliefs. They should also examine what there might be, within collective urban life, that mitigates against stress, whether that be the physical environment, mundane experiences in cafes and corner shops, informal friendships or forms of cooperative organisation. What kind of biopolitics might such a neurosocial and neurocultural understanding of urban existence enable?

As I argued at the start of this chapter, in the face of arguments about the prevalence of mental ill health in their own cities, urban policy makers have attempted to reverse this relationship, to make their city a place where individuals and communities can 'thrive'. So in these emerging programmes for healthy cities, are we seeing 'evidence-based' programmes and policies for mental health in urban settings?

Let me return to the Thrive programme. While there is much here to admire, it has to be said that it is remarkably evidence-light. Despite the wish to engage communities and build partnerships, most of the interventions are top-down and professional-driven. And rather than seeking to understand what it is in New York City, or in other cities, that drives people to mental ill health, the strategy starts from the existence of what are assumed to be mental disorders and emphasises the need for these to be recognised early, and for those with such disorders or at risk of them to have early access to professional mental health services in the name of prevention. Communities are important, but, for Thrive, they need to be trained by professionals: professionals collaborating with communities, training communities and so forth. Little attention is paid to the fact that in reality, the vast majority of care for people experiencing mental distress is, and will continue to be, provided informally, outside the professional sector. What we call primary care in health services is actually secondary care, coming into action only for those selected few who - by processes well studied by sociologists and anthropologists - come to the attention of medical or other authorities (Porter, 1985). And, to the extent that we can draw anything from the research on social capital and social exclusion, these local informal networks are often threatened, professionalised or demoralised by the incursion of professionals.

The kinds of research I have discussed here suggest other strategies to address the social determinants of mental distress in urban settings. The 
path to mitigating mental ill health, and to maximising mental wellbeing, does not lie through the mental health services or allied professionals as currently conceived: it lies in directly addressing those determinants in the light of more precise knowledge of the mechanisms through which they act, and by which they can be mitigated. It lies in understanding the capabilities that are required to lead a fulfilled life, and the resources necessary to realise these capabilities (Nussbaum, 2011). This may well require a complete reconstruction of mental health services, a retraining of professionals and greatly enhanced powers for those who have experienced mental distress and who understand mental health services from the point of view of those who have been their subjects - not an easy task but a necessary one if one is to learn the lessons from social research (Rose, 2018).

\section{In conclusion}

The Urban Brain programme is an experiment to see if it is possible to conduct such neurosocial and neurocultural research into specific and urgent socio-political questions. As I have said, it focuses on rural-urban migration in Shanghai and São Paulo, with comparators in the different migrant cities of Toronto and London. The research analyses epidemiological, psychiatric and ethnographic data, including our own research on mental health of migrants, to draw a thick picture of migrant life at work, at home and on the street. It uses conventional instruments to evaluate the mental health of a sample of the migrant population in different types of work and different forms of dwelling. It uses a range of measures to assess 'stress'. It involves partnership with psychiatrists, architects, artists and urban geographers to construct an 'urban mind' smartphone app to track mood across time and space, sampling both the physical environment and the urban sensorium. And it entails collaboration with other researchers working on the exposome and the microbiome, to obtain measures of the 'atmosphere' of the migrant city.

The research asks whether it is possible to rework Margaret Lock's idea of local biologies in ecological terms (Lock and Kaufert, 2001). While urban ecology is much derided these days, perhaps it could be helpful to think of the urban experience in terms of an array of niches, or habitats, what we term biological localities. The idea of a 'biological locality' helps us to rethink the dynamics and rhythms of urban spaces, as they make and remake exchanges of wealth and poverty, of power and 
exclusion, of exposures and atmospheres, of surveillance and security, of mobility and stasis, worry, anxiety, uncertainty and precarity, of community and isolation. In seeking to integrate biological and neurobiological insights and methods with older questions about inequality, poverty, exclusion, racism and violence, this research hopes to contribute to an urban biopolitics that does not focus on the diagnosis and therapeutics of the pathological individual, but addresses the pathogenic features of urban forms of life themselves. What might it mean to imagine 'the good city' through a neurosocial lens? Could we redeploy the language of biopolitics not for critique of metropolitan governments, but as a way to rethink the politics of health, stress and exposure in cities? If the urban experience is instantiated neurobiologically, a positive biopolitics of urban space would require us to think normatively, to ask whether a neurosocial style of thought might help us to clarify what we might hope for in shaping a good life, a flourishing life in the contemporary city.

\section{Acknowledgements}

This chapter draws on many discussions in the Neuroscience and Society Research Network and with my colleagues in the Urban Brain Project, including two recent papers written with Des Fitzgerald and Ilina Singh (Fitzgerald, Rose and Singh, 2016a; Fitzgerald, Rose and Singh, 2016b). It also draws on ongoing discussions with Nick Manning on questions of mechanisms (for more details see Manning, 2019). In addition to this, the chapter draws on research supported by the following grants: the European Union's Horizon 2020 Research and Innovation Programme funding for the Human Brain Project under Grant Agreement No. 720270; ESRC Award ES/L003074/1: A New Sociology for a New Century: Transforming the Relations between Sociology and Neuroscience, through a Study of Mental Life; ESRC-NSFC Award ES/N010892/1: Urban Transformations in China; and an award for Mental Health, Migration and the Mega City (Sao Paulo) - M3SP from King's-FAPESP APR Scheme.

\section{Notes}

1 See WHO, www.who.int/sustainable-development/cities/Factsheet-Citiessustainable-health.pdf?ua=1 (last accessed 1 November 2019).

2 For more information about the Urban Brain Programme, see https:// urbanbrainlab.com/ (last accessed 15 October 2019). This is also the topic 
of the book that I am writing with Des Fitzgerald called The Urban Brain: Mental health in the vital city, to be published by Princeton University Press in 2020.

3 For more information about South East London Community Health, see www.kcl.ac.uk/ioppn/depts/pm/research/selcoh/about/index.aspx (last accessed 15 October 2019).

4 With acknowledgements to the late Ian Dury: www.youtube.com/ watch?v=qcjh1a9Yoao (last accessed 15 October 2019).

5 For a quick introduction to contemporary beliefs about stress and toxic stress, see https://developingchild.harvard.edu/science/key-concepts/toxicstress/ (last accessed 15 October 2019).

6 Such as the ALSPAC study: www.bristol.ac.uk/alspac/ (last accessed 15 October 2019).

7 For example, the Urban Mind App, which we are helping develop in collaborator with Andrea Mechelli and his group at King's College London: www.urbanmind.info/ (last accessed 15 October 2019).

8 This was part of the rationale for the workshop in Rio de Janeiro at which a draft of this chapter was first presented.

9 See, for example, the figures illustrating stress pathways in McEwen and Stellar's classic paper in McEwen and Stellar, 1993, or Pescolido's diagram of the NEM III R (Network Episode Model) in Pescosolido, 2011.

10 My colleague Nick Manning points to the implications of the long-held belief that stomach ulcers arose from personality and lifestyle, rather than infection with Helicobacter pylori.

11 The following paragraphs are indebted to Ramsden's work, which he presented at our first Urban Brain workshop in 2013.

12 A tiny example: in our current research in Shanghai, a young women migrant from Shandong, in discussion with our resident ethnographer, Lisa Richaud, said how much she enjoyed travelling on the unbelievably crowded Shanghai metro in the rush hours, it gave her a feeling of collective momentum (dongli) and she liked feeling part of that.

13 'The Inflamed Mind' was the title of a BBC documentary in August 2016, available at www.bbc.co.uk/programmes/b07pj2pw (last accessed 15 October 2019).

\section{References}

Adams, J. and Ramsden, E. (2011). Rat cities and beehive worlds: Density and design in the modern city. Comparative Studies in Society and History, 53(4): 722-56.

Alam, R., Abdolmaleky, H.M., and Zhou, J. R. (2017). Microbiome, inflammation, epigenetic alterations, and mental diseases. American Journal of Medical Genetics Part B: Neuropsychiatric Genetics, 174(6): 651-60. 
Almedom, A.M. (2005). Social capital and mental health: An interdisciplinary review of primary evidence. Social Science \& Medicine, 61(5): 943-64.

Benton, T. (1993) Natural relations: Ecology, animal rights and social justice. London: Verso.

Bhugra, D., Tasman, A., Pathare, S., Priebe, S., Smith, S., Torous, J., Arbuckle, M.R., Langford, A., Alarcón, R.D., and Chiu, H.F.K. (2017). The WPA-Lancet Psychiatry Commission on the future of psychiatry. Lancet Psychiatry, 4(10): 775-818.

Burns, J. (2015). Poverty, inequality and a political economy of mental health. Epidemiology and Psychiatric Sciences, 24(02): 107-13.

Callon, M., Lascoumes, P., and Barthe, Y. (2009). Acting in an uncertain world: An essay on technical democracy. Cambridge, MA: MIT Press.

Campbell, P., and Rose, D. (2010). Action for change in the UK: Thirty years of the user/survivor movement. In D. Pilgrim, A. Rogers and B. Pescosolido (eds), The SAGE handbook of mental health and illness, 452-70. Newcastle: Sage.

Campion, J., Bhugra, D., Bailey, S., and Marmot, M. (2013). Inequality and mental disorders: Opportunities for action. Lancet, 382(9888): 183-4.

Cantor, D. and Ramsden, E. (2014). Stress, shock, and adaptation in the twentieth century. Rochester, NY: University of Rochester Press.

Dannenberg, A.L., Jackson, R.J., Frumkin, H., Schieber, R.A., Pratt, M., Kochtitzky, C., and Tilson, H.H. (2003). The impact of community design and land-use choices on public health: A scientific research agenda. American Journal of Public Health, 93(9): 1500-8.

Dantzer, R., O’Connor, J.C., Freund, G.G., Johnson, R.W., and Kelley, K.W. (2008). From inflammation to sickness and depression: When the immune system subjugates the brain. Nature Reviews Neuroscience, 9(1): 46-56.

Davidson, R.J., and McEwen, B.S. (2012). Social influences on neuroplasticity: Stress and interventions to promote well-being. Nature Neuroscience, 15(5): 689-95.

Dowd, J.B., Simanek, A.M., and Aiello, A.E. (2009). Socio-economic status, cortisol and allostatic load: A review of the literature. International Journal of Epidemiology, 38(5): 1297-1309.

Duhl, L. (1963). The urban condition: People and policy in the metropolis. New York: Basic Books.

Fassin, D. (2009). Another politics of life is possible. Theory, Culture \& Society, 26(5): 44-60.

Fitzgerald, D., Rose, N., and Singh, I. (2016a). Living well in the neuropolis. The Sociological Review Monographs, 64(1): 221-37.

Fitzgerald, D., Rose, N., and Singh, I. (2016b). Revitalizing sociology: Urban life and mental illness between history and the present. The British Journal of Sociology, 67(1): 138-60. 
Fone, D., White, J., Farewell, D., Kelly, M., John, G., Lloyd, K., Williams, G., and Dunstan, F. (2014). Effect of neighbourhood deprivation and social cohesion on mental health inequality: A multilevel population-based longitudinal study. Psychological Medicine, 44(11): 2449-60.

Fryers, T., Melzer, D., and Jenkins, R. (2003). Social inequalities and the common mental disorders. Social Psychiatry and Psychiatric Epidemiology, 38(5): 229-37.

Galea, S. (2011). The urban brain: New directions in research exploring the relation between cities and mood-anxiety disorders. Depression and Anxiety, 28: 857-62.

Galea, S., and Link, B.G. (2013). Six paths for the future of social epidemiology. American Journal of Epidemiology, 178(6): 843-49.

Galea, S., Uddin, M., and Koenen, K. (2011). The urban environment and mental disorders: Epigenetic links. Epigenetics, 6(4): 400-4.

Gong, Y., Palmer, S., Gallacher, J., Marsden, T., and Fone, D. (2016). A systematic review of the relationship between objective measurements of the urban environment and psychological distress. Environment International, 96: 48-57.

Grosz, E.A. (1994). Volatile bodies: Toward a corporeal feminism. Bloomington and Indianapolis: Indiana University Press.

Henderson, S., and Whiteford, H. (2003). Social capital and mental health. Lancet, 362(9383): 505-6.

Jackson, M. (2013). The age of stress: Science and the search for stability. Oxford: Oxford University Press.

Johnson, S.C., Cavallaro, F.L., and Leon, D.A. (2017). A systematic review of allostatic load in relation to socioeconomic position: Poor fidelity and major inconsistencies in biomarkers employed. Social Science \& Medicine, 192: 66-73.

Joseph, K. (1972). The cycle of deprivation. Midwife and Health Visitor, 8(12): 414.

Kelleher, C. (2003). Mental health and 'the Troubles' in Northern Ireland: Implications of civil unrest for health and wellbeing. Journal of Epidemiology and Community Health, 57: 474-5.

Kirk, R.G.W. (2014). The invention of the 'stressed animal' and the development of a science of animal welfare, 1947-86. In D. Cantor and E. Ramsden (eds), Stress, shock, and adaptation in the twentieth century, 241-63. Rochester, NY: University of Rochester Press.

Krabbendam, L., and Van Os, J. (2005). Schizophrenia and urbanicity: A major environmental influence - conditional on genetic risk. Schizophrenia Bulletin, 31(4): 795-9.

Link, B.G., and Phelan, J. (1995). Social conditions as fundamental causes of disease. Journal of Health and Social Behavior, extra issue: Forty years of medical sociology: The state of the art and directions for the future, 80-94. 
Lock, M., and Kaufert, P. (2001). Menopause, local biologies, and cultures of aging. American Journal of Human Biology, 13(4): 494-504.

Lund, C. (2014). Poverty and mental health: Towards a research agenda for low and middle-income countries. Social Science \& Medicine, 111: 134-6.

Lund, C., Breen, A., Flisher, A. J., Kakuma, R., Corrigall, J., Joska, J.A., Swartz, L., and Patel, V. (2010). Poverty and common mental disorders in low and middle income countries: A systematic review. Social Science \& Medicine, 71(3): 517-28.

Manning, N. (2019). Sociology, biology and mechanisms in urban mental health. Social Theory and Health, 17(10): 1-22.

McEwen, B. S. (2012). Brain on stress: How the social environment gets under the skin. Proceedings of the National Academy of Sciences, 109 (supplement 2): $17180-5$.

McEwen, B.S. (2013). The brain on stress: Toward an integrative approach to brain, body, and behavior. Perspectives on Psychological Science, 8(6): 673-5.

McEwen, B.S., and Stellar, E. (1993). Stress and the individual: Mechanisms leading to disease. Archives of Internal Medicine, 153(18): 2093-2101.

McKenzie, K., Whitley, R., and Weich, S. (2002). Social capital and mental health. British Journal of Psychiatry, 181(4): 280-3.

Meloni, M., Williams, S., and Martin, P. (2016). The biosocial: Sociological themes and issues. The Sociological Review Monographs, 64(1): 7-25.

Müller, N., Weidinger, E., Leitner, B., and Schwarz, M.J. (2015). The role of inflammation in schizophrenia. Frontiers in Neuroscience, 9: 372.

Muntaner, C. (2004). Commentary: Social capital, social class, and the slow progress of psychosocial epidemiology. International Journal of Epidemiology, 33(4): 674-80.

Nussbaum, M. C. (2011). Creating capabilities. Cambridge, MA: Harvard University Press.

Pariante, C.M. and Lightman, S.L. (2008). The HPA axis in major depression: Classical theories and new developments. Trends in Neurosciences, 31(9): 464-8.

Patel, V. and Kleinman, A. (2003). Poverty and common mental disorders in developing countries. Bulletin of the World Health Organization, 81(8): 609-15.

Patel, V., Lund, C., Hatherill, S., Plagerson, S., Corrigall, J., Funk, M., and Flisher, A. (2010). Mental disorders: Equity and social determinants. In E. Blas and A.S. Kurup (eds), Equity, social determinants and public health programmes, 115-34. Geneva: WHO.

Paykel, E., Abbott, R., Jenkins, R., Brugha, T., and Meltzer, H. (2000). Urbanrural mental health differences in Great Britain: Findings from the National Morbidity Survey. Psychological Medicine, 30(2): 269-80. 
Pescosolido, B.A. (2011). Organizing the sociological landscape for the next decades of health and health care research: The network episode model Iii-R as cartographic subfield guide. In B.A. Pescosolido, J.K. Martin, J.D. McLeod and A. Rogers, Handbook of the sociology of health, illness, and healing, 39-66. New York: Springer.

Phelan, J.C., and Link, B.G. (2010). Fundamental social causes of health inequalities. In C. Morgan and D. Bhugra (eds), Principles of social psychiatry, 181-92. Chichester: Wiley.

Phelan, J. C. and Link, B. G. (2013). Fundamental cause theory. In W.C. Cockerham (ed.). Medical sociology on the move, 105-25. London: Springer.

Porter, R. (1985). The patient's view. Theory and Society, 14(2): 175-98.

Ramsden, E. (2011). From rodent utopia to urban hell: Population, pathology, and the crowded rats of Nimh. Isis, 102(4): 659-88.

Ramsden, E. (2014). Stress in the city: Mental health, urban planning and the social sciences in the postwar United States. In D. Cantor and E. Ramsden (eds), Stress, shock and adaptation in the twentieth century, 291-319. Rochester, NY: University of Rochester Press.

Rapoport, A. (1978). Culture and the subjective effects of stress. Urban Ecology, 3(3): 241-61.

Rose, D. (2017). Service user/survivor-led research in mental health: Epistemological possibilities. Disability \& Society, 32(6): 1-17.

Rose, N. (2018). Our psychiatric future: The politics of mental health. Cambridge: Polity.

Rose, N., and Abi-Rached, J. M. (2013). Neuro: The new brain sciences and the management of the mind. Woodstock: Princeton University Press.

Rose, N., and Abi-Rached, J. M. (2014). Governing through the brain: Neuropolitics, neuroscience and subjectivity. Cambridge Anthropology, 32(1): 3-23.

Saegert, S., and Evans, G.W. (2003). Poverty, housing niches, and health in the United States. Journal of Social Issues, 59(3): 569-89.

Sartorius, N. (2003). Social capital and mental health. Current Opinion in Psychiatry, 16, S101-S105.

Selye, H. (1936). A syndrome produced by diverse nocuous agents. Nature, 138(3479): 32.

Senst, L., and Bains, J. (2014). Neuromodulators, stress and plasticity: A role for endocannabinoid signalling. The Journal of Experimental Biology, 217(1): 102-8.

Welshman, J. (2007). From transmitted deprivation to social exclusion: Policy, poverty and parenting. Bristol: Policy Press.

WHO (2014). Social Determinants of Mental Health. Geneva: WHO.

Wilson, E. A. (2015). Gut feminism. Durham, NC: Duke University Press. 